\title{
FESTAS, MAGNIFICAÇÃO E CHEFIA ENTRE OS KARAJÁ DO RIO ARAGUAIA
}

\author{
Parties, magnification and chieftainship among \\ the Karajá from Araguaia river \\ Fiestas, magnificación y jefatura entre \\ los Karajá del rio Araguaia
}

Helena Moreira Schiel ${ }^{1}$

\section{Resumo:}

Neste artigo pretendo demonstrar que a força que mantém aldeias grandes de forma mais perene é a produção de festas para filhos belos de famílias de prestígio, ou nobres. Acredito que este fenômeno, que é concebido pelos Karajá como a manifestação de riqueza de uma família, seja a base da manutenção de unidades políticas maiores. Para isso, procurei demonstrar que as características da chefia ameríndia, sugeridas por Pierre Clastres estão francamente corretas, mas são insuficientes para explicar a manutenção de grandes aldeias. Restaria explicar, justamente, diante de um potencial físsil tão grande, diante desta "força centrífuga" da máquina política ameríndia, como é possível o surgimento e a manutenção de aldeias grandes. Nosso argumento neste artigo é que tal é possível com a manutenção de uma vida alegre e pacífica na aldeia. Isto é possível mediante a produção contínua de festas e pelo reconhecimento público da beleza dos filhos de chefes.

Palavras-chave: índios Karajá, chefia, magnificação, festas

\begin{abstract}
:
In this article I have the intention of showing that the strength that keeps the big villages together for the longest time is the production of festivals for beautiful children of prestigious families, the nobles. I believe that this phenomenon, conceived by the Karaja as the manifestation of the wealth of a family, is the basis for the maintenance of bigger political units. For that, I tried to demonstrate that the characteristics of the Amerindian chief, suggested by Pierre Clastres, are frankly correct, but they are insufficient to explain the maintenance of the greater villages. I would like to explain, precisely how, facing a great potential of fracture and fission, given the "centrifugal force" of the indigenous political machine, how the dawn and maintenance of larger villages is possible. My argument in this article is that it is possible through maintaining a joyful and peaceful life in the village. This is made possible through a continued production of festivals and public recognition of the beauty of the children.
\end{abstract}

Keywords: Karajá, chieftainship, magnification, festivals

\footnotetext{
${ }^{1}$ Doutoranda em Antropologia Social na UFAM. Professora assistente na UFOPA.
} 


\section{Resumen}

En este artículo tengo la intención de demostrar que la fuerza que mantiene a los grandes pueblos más perennes es la producción de fiestas para hermosos hijos de familias prestigiosas, o nobles. Creo que este fenómeno, concebido por los Karajá como la manifestación de la riqueza de una familia, es la base del mantenimiento de unidades políticas más grandes. Para ello, traté de demostrar que las características de los dirigentes amerindios, sugeridas por Pierre Clastres son francamente correctas, pero son insuficientes para explicar el mantenimiento de las grandes aldeas. Quedaría por explicar, precisamente cómo, frente a un potencial fisionable tan grande, frente a esta "fuerza centrífuga" de la máquina política amerindia, cómo es posible emerger y mantener grandes aldeas. Nuestro argumento en este artículo es que esto es posible con el mantenimiento de una vida alegre y pacífica en el pueblo. Esto es posible a través de la producción continua de fiestas y por el reconocimiento público de la belleza de los hijos de los jefes.

Palabras clave: indígenas Karajá, jefatura, magnificación, fiestas

\section{Introdução}

Quando cheguei à aldeia Hãwalorá, nos primeiros dias andei por todas as casas para realizar um breve censo dos habitantes e das relações de parentesco que os uniam. Devido ao fato de a última aldeia em que eu havia estado ser fortemente dependente de empregos e bolsa-família, eu havia incluído nas perguntas do censo as fontes de renda de cada casa e se eles faziam roça. Na casa de Inãberu, uma das filhas do cacique, ao ser questionada sobre isso, ela começou espontaneamente a me enumerar os enfeites tradicionais das festas. Acabei precisando fazer um desenho a fim de localizar o uso de todos. Além disso, ela quis verificar se eu havia escrito corretamente. Claramente, Inãberu, ao ser indagada sobre as fontes de renda de sua casa, decidiu elencar suas fontes de riqueza. O que conecta os enfeites de festa, a concepção de riqueza e a "estabilidade política" entre os Karajá?

As abordagens de Pierre Clastres à política descreveram com muita acuidade as características do chefe ameríndio, quais sejam, suas prerrogativas da oratória, da generosidade e do apaziguamento de conflitos. Além disso, Clastres demonstrou que o chefe ameríndio seria um "chefe sem poder", ou seja, impossibilitado de exercer poder coercitivo. Se ele pretender impor sua vontade contra o desejo dos demais, será simplesmente abandonado. Sem pretender cair em singelas reiterações da literatura, pode-se dizer que tais características se encontram reproduzidas no chefe karajá e, também, nas suas relações com sua aldeia.

Entretanto, sempre me intrigou o fenômeno das grandes aldeias Karajá. Existem quatro delas com população superior a 600 pessoas, quais sejam, Macaúba, Canoanã, Fontoura e Santa Isabel do Morro. Além disso, a memória oral dá conta da existência de imensas aldeias no passado. Os descendentes de tais aldeias são orgulhosos deste passado glorioso. Como é possível, diante de um potencial físsil tão acentuado, a manutenção através do tempo de aldeias tão numerosas? No artigo que segue tentarei delinear respostas a esta pergunta a partir do fenômeno da magnificação, tal como foi proposto por Maurice Godelier na Melanésia. Este conceito tem sido trazido para a América do Sul em trabalhos como o de Renato Sztutman (2012), Aristóteles Barcelos Neto (2003) ou Antônio Guerreiro Jr. (2015).

Pretendo argumentar que, a despeito do alto potencial disruptivo da postura "contra-o-estado" dos Karajá, o amálgama que une uma população numerosa é a beleza dos filhos de chefes. E, também, as festas que são promovidas em honra dessas crianças. Não pretendo adentrar os debates em torno do conceito de arte, bastando, por ora, explicitar que entendo o efeito da produção de filhos de chefes belos como produzindo um efeito estético e político. 
Os Karajá são um grupo indígena da região do Rio Araguaia, etnograficamente situado na área conhecida como Brasil Central, falante de uma língua pertencente ao tronco Macro-Jê. Chamam a si mesmos de inã, termo que significa simplesmente "gente". Diferentemente da maioria de seus vizinhos Jê, suas aldeias não são circulares, mas em formato de linha ao longo do rio. Há também uma Casa dos Homens afastada da fileira de casas residenciais e voltada para a mata. Minha pesquisa junto a eles teve uma duração total de dezoito meses. Os dados aqui utilizados são oriundos sobretudo de minha estadia na aldeia Hãwalorá, aquela onde me detive por mais tempo, 5 meses.

As abordagens à chefia indígena nas Terras Baixas da América do Sul foram, em larga medida, influenciadas pelas ideias de Pierre Clastres. Para este autor, o chefe primitivo ${ }^{2}$ teria as características da oratória, do apaziguamento de conflitos e da generosidade. Em contrapartida ele receberia o privilégio da poliginia (CLASTRES, 1978, p. 27).

Na região da Melanésia, por sua vez, foi em torno da manipulação das riquezas e da performance pública do chefe que se formaram as concepções de chefia. Tomando um exemplo advindo da etnografia de Maurice Godelier na Papua-Nova Guiné, o chefe baruya teria herança de chefia, ou seja, seria filho de linhagem de chefes, mas deveria demonstrar publicamente sua capacidade de promover uma boa vida a seu povo

para além desta hierarquia linhageira hereditária (...) se abre um vasto domínio onde podem se expressar as capacidades desiguais dos diversos indivíduos de cada geração a assumir três funções indispensáveis à reprodução da sociedade: a guerra, a caça e o xamanismo. Estas atividades são o domínio por excelência da seleção e promoção de homens que se distinguem ao longo de sua vida da massa de homens ordinários (GODELIER, 1996, p. 132. Tradução da autora)

A isso o autor atribui a ideia de "poderes herdados, poderes merecidos".

No caso que estou abordando, dos Karajá do Brasil Central, a chefia tem as características destacadas por Clastres ao mesmo tempo em que eles possuem herança familiar e performances públicas, tal como o Big Man melanésio. Pretendo argumentar que a influência de um chefe Karajá é confirmada através da manifestação pública da beleza de seus filhos, bem como da manutenção de intensa atividade ritualística e festiva. Lanço mão, aqui, da proposta de Marc Brightman de se pensar o exercício político do chefe ameríndio não pelo fenômeno do poder mas pelo da influência:

Considero a importância da liderança na organização de relações entre pessoas, grupos, objetos e lugares entre os Trio, Wayana e Akuriyo. Mostro que a habilidade individual de manter acesso privilegiado ou controle sobre essas coisas constitui uma fonte de poder. Este é o poder de influenciar, organizar e promover a integridade e a "boa vida" da coletividade. (BRIGHTMAN, 2007, p. 3. Tradução da autora)

A associação da magnificação à confirmação da influência política, tema este recorrente na etnografia da Melanésia, tem sido abordada por alguns autores no Brasil. Renato Sztutman lançou mão do conceito de magnificação ao abordar o ritual antropofágico dos Tupinambá seiscentistas. O ritual antropofágico era a oportunidade de se ganhar nomes, nobreza, esposas. Na festa residia a possibilidade da

\footnotetext{
${ }^{2} \mathrm{O}$ conceito de primitivo em Clastres ora se molda ao indígena sul-americano da região tropical, ora se afasta, figurando como uma espécie de tipo ideal weberiano. Esta conceitualização não é assunto deste artigo, mas considero importante explicitar que estou tomando o termo primitivo de Clastres como sinônimo de ameríndio, à revelia da concepção cambiante do autor.
} 
construção da pessoa do guerreiro e na possibilidade de sua magnificação (SZTUTMAN, 2012, p. 193). Na área etnográfica do Alto Xingu, vizinha ao interflúvio Tocantins-Araguaia onde minha pesquisa se desenrola, a herança nobre e a performance que possibilitam confirmar a chefia foram abordadas por Antônio Guerreiro Jr. e Aristóteles Barcelos Neto.

Para Barcelos Neto, em abordagem a um conjunto ritual Wauja, a chefia possui uma substância nobre. “Todo amunaw, antes de ser propriamente um chefe político, é alguém que possui substância amunaw". (BARCELOS NETO, 2008, p. 263). Mas seria necessário potencializar esta substância através de rituais ou do patrocínio de rituais públicos. Um grande chefe Wauja não seria alguém com excepcional quantidade dessa substância nobre, amunaw, mas alguém que "conseguiu potencializar a que herdou, mesmo que não seja muita" (idem, p. 266).

Guerreiro Jr., em sua abordagem ao ritual funerário do kwarup entre os Kalapalo, indica que produzir um chefe, anetü, tarefa dos nobres, significa produzir a pessoa ideal, "alguém que possa ser chamado de 'gente' (kuge) em comparação aos demais: pois 'gente', sem qualquer qualificação, quer dizer simplesmente chefe" (GUERREIRO JR., 2015, p. 153). O autor faz notar que a existência de aldeias "de verdade", para os Kalapalo, "(com casa dos homens e capazes de patrocinar rituais) duráveis é a condição para a produção do parentesco, pode-se dizer [então] que a produção do parentesco está condicionada à existência de chefes” (idem, p. 169).

O Alto Xingu fornece um contraponto bastante interessante aos Karajá. Estes poderiam ser tanto incluídos quanto excluídos das "variações sobre o mesmo tema Macro-Jê”. Pois apresentam um dualismo concêntrico, como alguns de seus vizinhos Jê, mas que se alterna com um triadismo classificatório (cf SCHIEL, 2012). Para compreender os aspectos que os diferenciam dos grupos Jê do Brasil central, aposto na aproximação com os modelos alto-xinguanos. É ali que acredito residir o maior potencial explicativo para as comparações com o fenômeno da chefia Karajá.

\section{Nobres, "ricos", belos}

O "Você é tori i-tyhy rioré?" me perguntou Lahiri, filho do cacique de Hãwalorá. Eram meus primeiros dias na sua aldeia, quando eu já começava a ter alguma familiaridade com o seu dia a dia. Naquele momento eu já compreendia algo de sua língua inãrybé, "fala de gente". Respondi com outra pergunta de esclarecimento: "Você quer saber se sou tori de verdade (tyhy) ou você quer saber se sou rica?". Lahiri pareceu se regozijar de eu compreender a amplitude do campo semântico de " $i$-tyhy" e esclareceu que queria mesmo era saber se minha família era grande e rica. Tori, branco ${ }^{4}$, aqui representava uma espécie de distintividade étnica. Se a mesma pergunta fosse dirigida a um Tapirapé, que é chamado de woku, seria "woku i-tyhy rioré". Ritxoré é a palavra para "filho" (rioré na pronúncia masculina) e tyhy um adjetivo intensificador, equivalente na maior parte das vezes a "verdadeiro", mas podendo também significar forte ou intenso. No caso, a tradução da pergunta poderia ser tanto "Você é filha de tori mesmo?" quanto "Você é filha de tori rico?".

\footnotetext{
${ }^{3}$ Como mencionado por Aracy Lopes da Silva, "uma das possibilidades mais fascinantes do estudo das sociedades Jê é, sem dúvida, a da análise comparativa em que se pode perceber a variedade de construções sociais a partir de certos temas básicos e de um acervo de elementos recorrentes entre os vários grupos Jê. A comparação tem, ao mesmo tempo, dois produtos complementares: leva à generalização que, no caso, significa a compreensão e expressão do 'padrão' Jê; e permite a percepção, em cada sociedade particular, de certos aspectos que na sua configuração geral são obscurecidos ou de difícil captação mas que, em uma outra sociedade jê, têm expressão clara e privilegiada, inclusive pela importância que os próprios atores Ihe conferem" (LOPES DA SILVA, 1986, p. 183).

${ }^{4}$ O termo tori quer dizer "não-índio" em karajá mas eles preferem a glosa "branco", uma espécie de forma genérica do não-índio.
} 
Pretendo demonstrar aqui que a concepção de riqueza dos Karajá está centrada na produção de filhos belos para quem se dedicam pequenos e grandes rituais. Apenas famílias numerosas e com grandes posses materiais são capazes de manter uma vida ritual plena. E a manutenção de uma chefia perene depende diretamente da produção de filhos belos e de festas em honra deles. Um chefe é necessariamente um homem com muitos filhos e netos, com uma família laboriosa e promotor de grandes rituais. Neste caso, nenhum dos dois elementos - família laboriosa e abundância material - precede o outro. Aparentemente os dois elementos se retroalimentam.

Há quatro categorias tradicionais que designam chefia ou liderança entre os Karajá. A mais comum para designar uma liderança é o sufixo wedu, ou seja "dono". É uma categoria comum aos povos indígenas das Terras Baixas da América do Sul (FAUSTO, 2008). Ela se aplica a líderes de certas atividades ou pessoas que se destacam numa determinada atividade como promoção de festas, torneios de futebol, ou mesmo atividades menos ritualizadas como capinar o mato que cresce nos caminhos entre as casas residenciais das aldeias. Ixãwedu, que pode ser traduzido como o "dono do povo", seria a categoria de chefia que media a relação com espíritos durante os rituais. Há também a categoria de ixãdinodu que corresponderia a uma espécie de "dono da aldeia", uma categoria mais mundana (TORAL, 1992, p. 79). A tradução mais corrente da palavra em português seria "cacique". Os Karajá ainda se valem da terminologia trazida pelo exército, de "capitão", ou

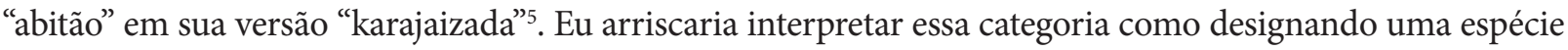
de diplomata, que media as relações com os coletivos exteriores, sobretudo os tori, os não-índios.

Nas quatro maiores aldeias Karajá, mencionadas no início deste artigo, existe o cargo de ixãtyby, termo que pode ser traduzido como "pai do povo". Líderes de famílias extensas, em geral já idosos, são muito queridos pelas comunidades. Atuam nos rituais, com uma performance formal, indicando as atividades necessárias para a execução dos ritos. No ritual de iniciação masculina são chamados de "pai da casa grande”. É na formalidade de sua atuação que vemos se destacar sua figura. Enquanto atuando como ixãtyby eles devem se locomover nos ombros de outros, seguidos por uma espécie de séquito. Seus pés não tocam o chão. Ao parar a comitiva, ele é depositado sobre uma esteira.

Até onde compreendo, o ixãtyby é herdeiro de família nobre. Não encontrei um termo nativo que corresponda a nobreza. Mas as famílias de onde saem os ixãtyby e os ioló em geral habitam a parte central da fileira de casas residenciais. Há uma franca preferência por casamentos entre famílias nobres. Segundo Fénelon Costa, Arutana, talvez o último ixãtyby de renome para além da aldeia, era filho de outro ixãtyby e casado com uma filha de chefe (COSTA, 1978, p. 9).

Alguns filhos ou netos destes ixãdinodu são criados como ioló ${ }^{6}$. O ioló é necessariamente uma pessoa boa, pacífica. Há sempre uma expectativa de que os ioló assumam, quando adultos, cargos de chefia. É uma criança tida como especial, de família nobre (ou -ityhy, como diria Lahiri, mencionado acima), rica, especial,

\footnotetext{
${ }^{5}$ A língua Karajá, o inãrybé, faz uma distinção na pronúncia segundo o gênero da pessoa que está falando. Em geral um " $\mathrm{k}$ " ou um " $t x$ " entre duas vogais ou no começo de uma palavra começada por vogal, para as mulheres. Dessa forma, céu seria biku para mulheres e biú para homens. Filho seria ritxoré (ou rikoré dependendo da variante) para mulheres e rioré para homens. Kayapó seria karalahu para mulheres e aralahu para homens. Quando as patentes de exército foram "distribuídas" nas aldeias, o termo capitão entrou na lógica da língua inãrybé e passou a ser pronunciado abitão pelos homens.

${ }^{6}$ Por muito tempo eu grafava as palavras em sua versão masculina e às vezes notava a versão feminina dela. Entretanto, à medida que meu domínio da língua foi melhorando, os próprios Karajá me exigiam a pronúncia - e a grafia - dos termos em sua versão feminina. Adotei a exigência na grafia dos diários de campo e dos textos subsequentes. O termo ioló tem uma versão feminina, ikoloku. Entretanto escutei pouquíssimas vezes esta versão. Talvez o esmaecimento do termo siga o ocaso da própria função. Em todo caso, opto aqui por grafar o termo da maneira como me acostumei a ouvi-lo, que é sua versão masculina, ioló.
} 
“de verdade". Ele era criado de forma diferente das outras crianças. Não brincava com os outros. Não se banhava no rio e sim em uma bacia (panela de barro) com água que lhe era trazida. A mãe enfeitava o menino e ele era instruído a se mover o mínimo possível. Imóvel, sentado e belo, esse era o "príncipe" karajá7.

\section{Alteridade e movimento}

As concepções de identidade e alteridade, entre os Karajá, têm uma clara associação com as ideias sobre mobilidade. Com efeito, para os Karajá, há uma associação simbólica entre imobilidade e identidade, e mobilidade e alteridade. Eduardo Viveiros de Castro nos adverte de que "a identidade é um caso particular da diferença (...) O que equivale a dizer que só existe diferença, em maior ou menor intensidade" (VIVEIROS DE CASTRO, 2002, p. 422). Por essa razão prefiro expressar essas associações simbólicas dos Karajá em termos de um gradiente de mobilidades, e por conseguinte um gradiente de alteridades possíveis.

O mundo de origem, na concepção cosmogônica, fica no fundo do rio. É um lugar de fatura e de convívio entre consanguíneos. É um local muito molhado, a água bate no joelho. Neste local não há morte, mas há nascimentos. Por isso mesmo é um lugar superlotado. Difícil de se mover. Os seres que aí vivem, ancestrais da humanidade, estão sempre sentados em seus banquinhos.

Outros patamares cosmológicos revelam os aspectos simbólicos dos outros tipos de mobilidade. A saída do mundo de origem se deveu justamente ao encanto com os espaços amplos do mundo terrestre. Com a possibilidade de mobilidade. Mas a contrapartida dessa abundância de espaço foi a morte. Um dos primeiros a sair do fundo das águas, Koboí, ao ver troncos de árvore secos, disse que aquele lugar era ruim pois havia morte. E decidiu retornar ao fundo das águas. É também no patamar terrestre que estão localizados os mundos dos mortos. Destino post-mortem das pessoas comuns.

As pessoas que morrem de causas comuns, quais sejam, doença e feitiço (que são ali praticamente sinônimos) vão para um local semelhante ao mundo terrestre. Há aldeia e casas, mas tudo é podre. Faz muito frio e a chuva é muito quente. O rio que corre nessa aldeia tem a cor opaca. É preciso trabalhar muito para comer e os instrumentos de trabalho são todos podres, furados. Essas almas vivem com saudades de seus parentes vivos, mas nesse local são todos afins e estão em constante conflito e movimento.

As pessoas que morrem derramando sangue, ou seja, assassinadas, têm o destino post-mortem mais terrível. Uma aldeia contígua à primeira aldeia dos mortos. Nesta faz muito frio e a chuva é muito quente. A coloração do rio é vermelha. A comida é sempre crua, não há roça. Os seres que aí estão não são consanguíneos nem afins e, se encontram outros, começam a lutar. Eles permanecem com as chagas que lhes mataram vivas e sangrando. Eles estão em constante movimento. Segundo Patrícia Rodrigues, eles não são nem consanguíneos nem afins e "ficam sozinhos". (RODRIGUES, 1993, p. 408-409).

Ora, é na concepção de mundo post-mortem do céu que encontramos aquilo que chamarei de mobilidade ideal. O céu, ou mundo das chuvas, é o lar de seres belos, morada do demiurgo Kanãxiwé e destino post-mortem dos xamãs que só revelam a parte boa do xamanismo: a cura. Neste local, concebido como perfeito, as casas são distantes umas das outras, todas feitas de pedra. É um lugar muito luminoso. Não é preciso trabalhar para comer, pois as flechas caçam sozinhas. Os seres que aí vivem estão sempre belamente adornados e passam todo o tempo dançando com suas lerã teheriare, irmãs distantes, ou seja, afins potenciais.

Temos então uma espécie de gradiente entre tipos distintos de mobilidade, entre a imobilidade do mundo de origem, associada à identidade (ou "menos alteridade"), as mobilidades do mundo terrestre, a co-

\footnotetext{
${ }^{7}$ Muitas vezes obtive essa tradução para o termo ioló, o que denota seu caráter nobre, diferente dos comuns
} 
mum do mundo dos vivos, as mobilidades extremas dos dois mundos dos mortos e finalmente a mobilidade ideal do mundo das chuvas, que vem a ser a dança. É no mundo perfeito, de harmonia entre afins e consanguíneos, que se encontra a mobilidade perfeita, a dança. O corolário dessa mobilidade ideal da dança é que o mundo perfeito do céu é um mundo de festa. Os seres que aí vivem estão sempre belos, bem adornados.

A imobilidade do ioló, sentado em seu banquinho, carrega um simbolismo muito claro de expressão da identidade. Esta imobilidade evoca imediatamente o mundo de origem. Em princípio o fenômeno ioló juntava-se para mim àquelas referências de um passado glorioso do qual coletamos histórias, registrada nas memórias, mas que não está mais acessível à observação. Porém, ao indagar, certa vez, na aldeia Macaúba a uma senhora o que era o ioló e se ainda havia crianças criadas desta forma, para minha surpresa, a senhora indicou uma criança da aldeia Hãwalorá como ioló. Ela acrescentava "a mãe dele sabe fazer enfeite. O menino está sempre bonito".

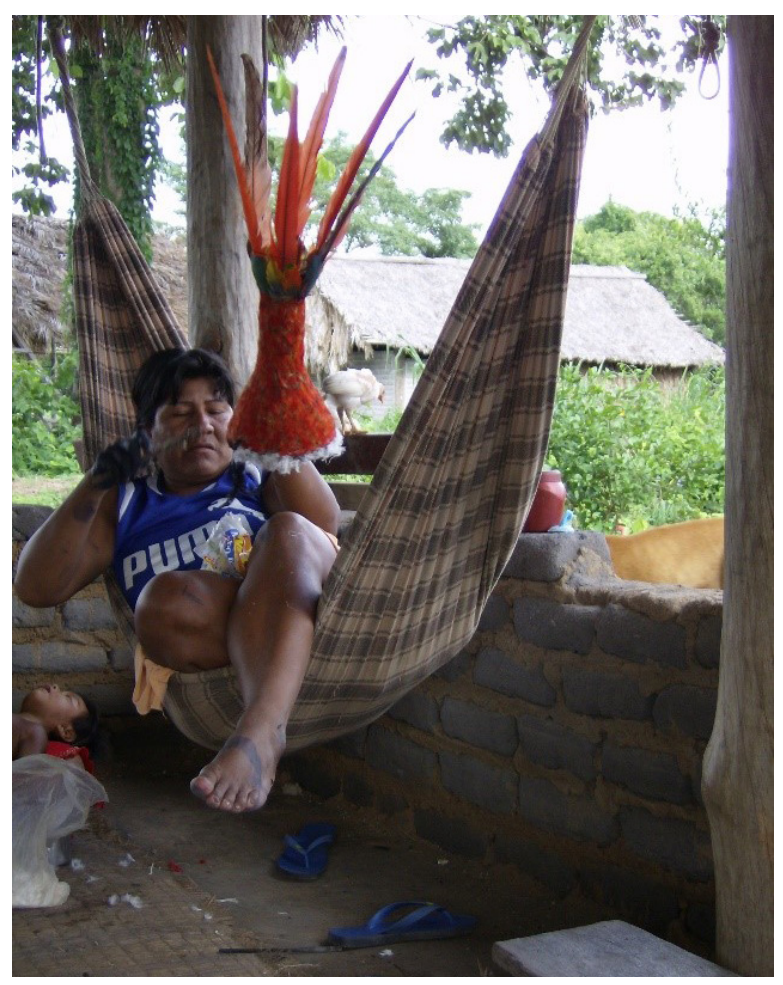

Figura 1 - Hariwiru preparando um cocar para seu neto. Foto da autora. Aldeia Hãwalorá, dezembro de 2012.

O menino a que se fazia referência era um bisneto do cacique Carlos Waximakuri. A avó do menino, Hariwiru, filha primogênita do cacique, está sempre ocupada em preparar enfeites. Exerce uma ampla influência sobre seus irmãos. É à sua casa, ou seu "terreiro", que acorrem os irmãos e pais no fim da tarde para conversar, bem como alguns outros membros da aldeia, sem relação direta de consanguinidade. Ela está sempre preparando os enfeites para as festas, os saiotes de palha com que os homens jovens dançam, trançando esteiras e costurando os adornos como pulseiras, perneiras. Mas sobretudo, ela mantém seus netos sempre belos, mesmo em situações cotidianas, fora do ritual. Em nenhum momento o menino me foi designado como ioló por seus familiares. Entretanto, o reconhecimento de sua beleza vai além da sua aldeia e é assim entendido por vizinhos.

Como mencionei no início deste artigo, ao indagar em uma das casas de Hãwalorá as fontes de renda da família, Inãberu, a dona da casa espontaneamente passou a me listar os enfeites tradicionais dos Karajá. 
Os enfeites tradicionais incluem a pulseira deixi, e o dekobuté, pintados com urucum, uma perneira que se amarra abaixo do joelho. Um enfeite com longas franjas pretas que se amarra no braço, loru. Colares de miçanga, myraní, brincos de pena, kuedju. O menino que passa pela iniciação masculina é em geral o que mais se vê enfeitado com a indumentária mais completa e, por que não, mais rica que um Karajá pode proporcionar. Ora, descrever sua fonte de "renda", para Inãberu, significava enumerar a riqueza de sua família. E seus conhecimentos sobre a confecção dos enfeites, a lista que ela fez questão que eu anotasse eram uma espécie de extrato do que sua família possui. Conhecimentos tradicionais, beleza, influência.

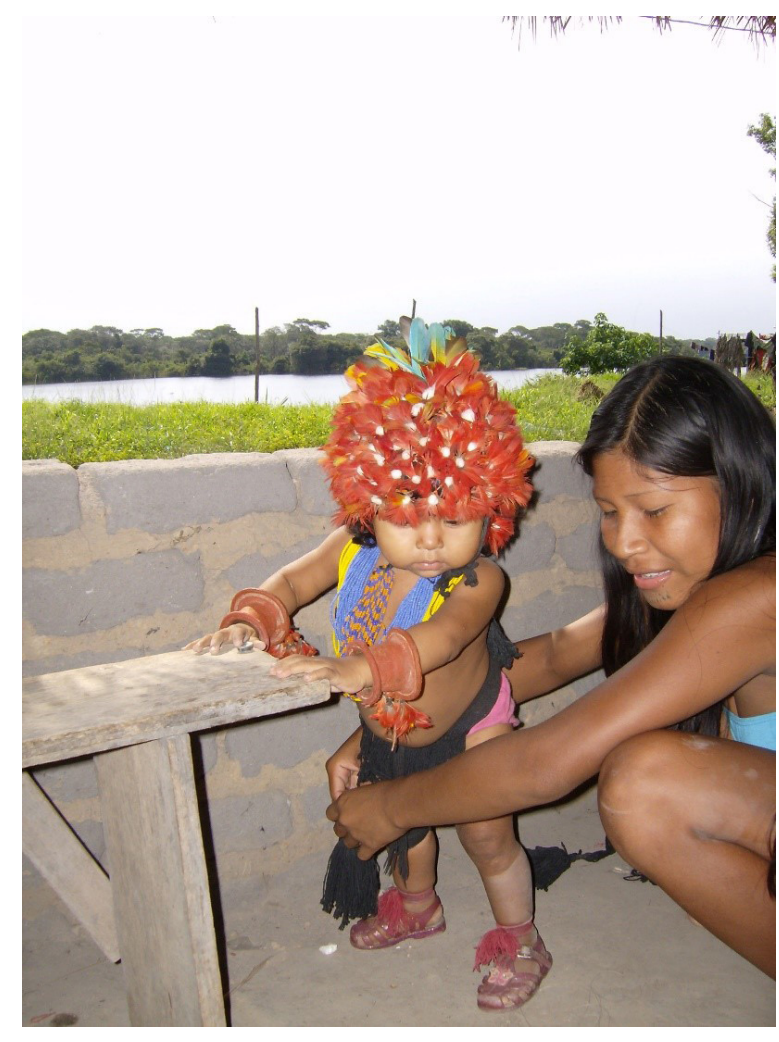

Figura 2 - Neta de Hariwiru usando todos os seus enfeites/riqueza junto à sua mãe. Foto da autora. Aldeia Hãwalorá, dezembro de 2012.

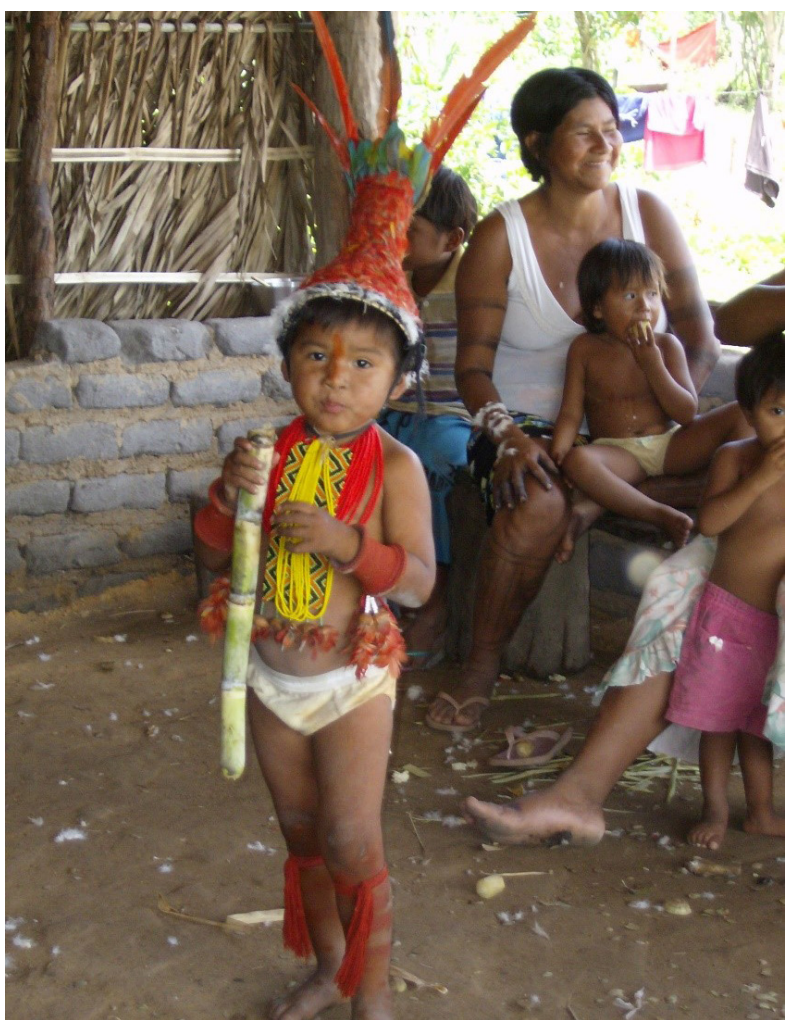

Figura 3 - Neto de Hariwiru com seus enfeites/riqueza. Referido por aldeia vizinha como ioló. Foto da autora. Aldeia Hãwalorá, dezembro de 2012.

A chefia Karajá, como uma variante da chefia ameríndia, deveria possuir as características abordadas por Clastres, ou seja, a generosidade, a capacidade de apaziguar conflitos: "essencialmente encarregado de resolver os conflitos que podem surgir entre indivíduos, famílias, linhagens, etc., ele só dispõe, para restabelecer a ordem e a concórdia, do prestígio que lhe confere a sociedade. Mas evidentemente esse prestígio não significa poder" (CLASTRES, 1978, p. 144). E como é de se supor, possui também aquela característica da extrema dissolubilidade. Um chefe está sempre à mercê das críticas e se não corresponde à vontade geral, ele se arrisca a não ser chefe de nada.

Ora, diante de tal cenário, que parece um pouco banal diante dos já exaustivamente descritos sistemas políticos ameríndios, sempre me surpreendeu justamente o fenômeno contrário. Não o potencial físsil das aldeias, mas a existência e permanência de aldeias grandes. Os Karajá possuem quatro aldeias muito grandes, com mais se 600 pessoas. Canoanã, entre os Javaé, Macaúba, Fontoura e Santa Isabel, entre os Karajá propriamente ditos. 


\section{Festas}

Karajá possuem dois ciclos festivos fundamentais: a iniciação masculina, que nas aldeias grandes é o Hetohokã, o mais completo ciclo de iniciação, e as danças de aruanã, ou ijasó Anarakã. Ijasó é o nome do espírito dos ancestrais, que habitam o fundo do rio, e também do peixe aruanã (Osteoglossum bicirrusum). Anarakã é um termo genérico para festas e atividades ritualísticas. Se fosse encontrar uma glosa em português, optaria por "brincadeiras", que é como os Karajá geralmente exprimem o espírito dessas festividades. Opto entretanto pelo termo genérico "festas", para facilitar a compreensão.

De duração aproximada de um ano, as danças de aruanã e a iniciação masculina se entrelaçam. Para além delas, há alguns ritos de passagem ${ }^{8}$ que não têm periodicidade anual e dependem tanto da maturação de certos ciclos individuais quanto da disposição de alguém em patrociná-los. São eles a festa da primeira comida, quando um bebê se alimenta com alimento sólido pela primeira vez, por volta dos seis meses. A festa da ijadokomá, moça, quando, após a primeira menstruação da menina, ela sai da reclusão pubertária. Há também a visita esporádica de um espírito de um guerreiro inimigo, que se torna protetor da comunidade. Esta festa é chamada de Woku no médio e alto Araguaia e Karalahu no Baixo Araguaia. Tal variação de nomes indica quem é este inimigo preferencial em cada região. Woku significa Tapirapé e Karalahu, Kayapó.

Toda festa tem um wedu, dono. É sempre uma criança de família de prestígio. Os pais da criança são patronos do ritual. Ser presenteado com um espírito ou aceitar levar o filho a passar por um ritual completo implica em uma grande demanda de trabalho e articulação da família extensa. Para patrocinar o ritual é necessário mobilizar os esforços da família toda. Para as iniciações masculina e feminina, bem como a festa da primeira comida, é preciso confeccionar esteiras onde irá se desenrolar a cena mais ritualística da festa.

As festas devem necessariamente ser providas de farta alimentação. Tanto alimentos tori como bolachas, bolo, refrigerantes, quanto alimentos inã (Karajá) como macaxeira cozida, peixe assado, farinha. Apenas no Hetohokã eu registrei queixas sobre o uso de alimento tori nas festas. Na aldeia Santa Isabel ouvi elogios ao Hetohokã da aldeia Fontoura, onde os alimentos eram tradicionais, porque "lá o pessoal não tem preguiça, tem roça grande mesmo".

Além de muita comida, esteiras e enfeites, há os brotyré. Brotyré é uma categoria de parentes da criança a quem é atribuída a função de proteger o corpo da criança ${ }^{9}$. Tanto proteger de espíritos maléficos, de ação de xamãs maldosos quanto proteger seu corpo. Os brotyré de uma criança não podem ser de sua própria geração (G0 excluída) e também não podem ser seus pais. Em geral, tios, tias, avós. Por sua ação no ritual, os brotyré têm direito a uma retribuição material, um presente.

Descreverei em linhas gerais a festa da primeira comida, retirando os elementos essenciais para a compreensão da produção da riqueza e reprodução do prestígio das famílias nobres, gente de verdade, inãityhy.

Quando cheguei à Hãwalorá, no início de abril de 2009, aquela festa da primeira comida tinha acabado de ser realizada. O pai do bebê, Lawari, é filho do cacique Carlos Waximakuri. Ele me mostrou sua casa e chamou atenção para o fato de que estava quase completamente vazia. Os bens materiais haviam se dispersado pela aldeia por ocasião da festa. Os bens mais valiosos que ele "perdeu" ali foram uma bicicleta e uma canoa. Parece-me que, para além de um certo lamento de perder seus bens materiais, havia uma considerável dose de orgulho ao me enumerar todas as coisas que haviam sido objeto de doação ao final da festa: esteira, colchão, rede, canoa, bicicleta, panelas. Além disso, ele iria depender da casa de sua irmã por um tempo para se alimentar, uma vez que na sua sequer havia panelas. Xeãa uma Tapirapé que vive em Hãwalorá, relata que

\footnotetext{
${ }^{8}$ Utilizo aqui a terminologia sugerida por Van Gennep (2011) e retomada por Victor Turner (1974).

${ }^{9}$ Pronuciada borotyré entre os Javaé.
} 
algumas vezes a casa fica tão sem recursos ao final de uma festa que algumas pessoas próximas se compadecem e devolvem, às escondidas, alguns bens que haviam sido levados. Ruth, uma senhora da aldeia Macaúba, me disse que muitas pessoas não realizam os rituais para seus filhos "porque têm medo do brotyré".

Seguindo a análise clássica proposta por Arnold Van Gennep ${ }^{10}$, a festa da primeira comida pode ser considerada um rito de passagem. Ela é composta por um momento de separação, quando as famílias patri- e matrilaterais, a elas adicionados os eventuais convidados que não são da família, acorrem à casa da criança. Há uma fase liminar para os brotyré, os pais e o bebê: trata-se daquele momento em que todos estão sentados na esteira. Esta é certamente a etapa mais complexa do rito.

O sentar-se na esteira, gesto comum a praticamente todos os rituais karajá, marca o que Victor Turner ${ }^{11}$ chamaria de momento de "indiferenciação" da fase liminar de um ritual. Ou seja, uma ausência de marcadores que distinguem as pessoas que compõem o corpo de brotyré. Quero aqui sugerir a interpretação desse fenômeno como a produção de um "corpo coletivo" composto pelos parentes bilaterais. Este corpo é uma proteção para o bebê. Naquele momento os indivíduos deixam de ter destaque e passam a compor isto a que estou chamando de corpo coletivo. Os dados sugerem que toda vez que o corpo coletivo do brotyré - que é diferente para cada criança - se compõe, são reforçados os laços que unem aqueles indivíduos.

Finalmente, há uma fase de reagregação. Após a comida ser liberada e todos obterem o alimento que conseguem, ocorre a distribuição de bens e o retorno às casas. Neste momento o corpo coletivo se desfaz. Entretanto ele já não é o mesmo que entrou no ritual. O partilhar do alimento em torno do bebê reforçou entre eles esses laços. O ritual parece funcionar como um dos amálgamas que auxiliam a manutenção da vida coletiva.

Além disso, sugiro que a proeminência do pai da criança esteja em destaque aqui. Sua presença na festa é bastante discreta. A preparação é toda desenvolvida na esfera feminina da família extensa. A execução do rito em si é obra das avós. E, afinal, a festa é em honra de um filho bebê. Entretanto, é a capacidade daquele homem de prover os insumos para todo esse preparo que está em jogo. Ademais, ele não escolheria honrar seu filho bebê em uma festa caso não dispusesse de bens materiais a serem dispersos ao final dela.

Neste ponto descreverei o sistema de dádivas envolvido na festa para sugerir a proeminência do pai da criança. Sempre me intrigou o sistema de dádivas envolvido no fenômeno brotyré. O brotyré, como mencionado anteriormente, é um grupo de parentes que se dispõe a proteger a criança, assegurar seu crescimento saudável. Para fins de "tradução cultural" eu penso os brotyré como uma espécie de padrinhos, parentes mais ou menos próximos que têm uma relação especial de proteção com a criança. Mas a palavra é polissêmica e se aplica também ao presente em si, que é retribuído aos parentes que vêm proteger o filho. E é usada também para descrever o ato de se oferecer para proteger a criança: "vou fazer brotyré" é o que eles dizem.

No caso das festas, que é quando se ativa de forma mais intensa o que vou chamar aqui de "sistema brotyré", um pequeno sistema de dádivas é posto em ação. Um parente ou vizinho diz "vou fazer brotyré para seu filho". O "fazer brotyrê" nesse caso pode ser o sentar-se na esteira durante o ritual. Mas pode também ser sen-

10 "Dada a importância destas passagens, acredito ser legítimo distinguir uma categoria especial de Ritos de Passagem, que se decompõem, quando submetidos à análise, em Ritos de separação, Ritos de margem e Ritos de reagregação. Estas três categorias secundárias não são igualmente desenvolvidas numa mesma população nem em um mesmo conjunto cerimonial. Os ritos de separação são mais desenvolvidos nas cerimônias dos funerais, os de reagregação, nas do casamento. Quanto aos ritos de margem, podem constituir uma seção importante, por exemplo, na gravidez, no noivado, na iniciação" (VAN GENNEP, 2011, p. 29-30).

11 “Os atributos de liminaridade, ou de personae (pessoas) liminares são necessariamente ambíguos, uma vez que esta condição e estas pessoas furtam-se ou escapam à rede de classificações que normalmente determinam a localização de estados e posições num espaço cultural. As entidades liminares não se situam aqui nem lá; estão no meio e entre as posições atribuídas e ordenadas pela lei, pelos costumes, convenções e cerimonial." (TURNER, 1974, p. 117). 
tar-se junto ao vizinho e comer alguma coisa de sua comida, tomar seu café. Por ter "feito brotyré" para o filho (tomado café do vizinho, por exemplo), tem-se o direito de pedir algo em troca. Um presente, uma dádiva.

A pergunta que sempre me ocorre quando eu testemunho esses momentos é: o que está sendo retribuído aos pais da criança quando eles fornecem alimento e presentes aos brotyré de seus filhos?

Gostaria de separar aqui as fases do sistema de dádivas que, segundo proponho, estão em jogo no fenômeno brotyré, a fim de tentar responder a essa pergunta. Segundo a análise clássica de Marcel Mauss, os três movimentos da troca são obrigatórios: a obrigação de dar, a obrigação de receber e, também, de retribuir (Mauss, 2013, p. 69). Ao se receber uma dádiva, contrai-se uma dívida: há a obrigação de receber. Veja-se que não é uma opção e sim uma obrigação de receber. Para quitar-se esta dívida surge a necessidade de se retribuir. No sistema brotyré, os pais convidam para a festa os brotyré de seus filhos. Os brotyré se sentam na esteira e comem o alimento ofertado pelos pais. Em retribuição ao fato dos brotyré terem aceitado o convite, sentado e comido o alimento, os pais oferecem um presente material. $\mathrm{O}$ sistema foi esquematizado aqui abaixo, mostrando com setas o movimento das dádivas. Abaixo da seta que indica o movimento da dádiva, descrevo o que está sendo dado.

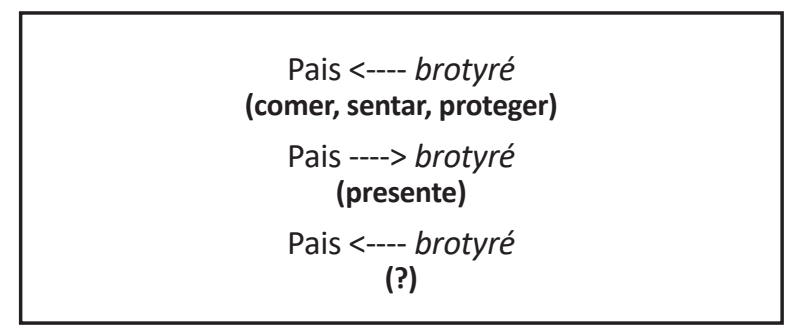

Figura 4 - ciclo de dádivas do brotyré

Resta uma incógnita: o que os pais recebem em retribuição à sentada e partilha do alimento, ofertada pelos brotyré? Eu gostaria de argumentar aqui que nesta e em todas as festas em que o sistema brotyré é colocado em ação, o que os pais recebem em retribuição é um presente imaterial. É o prestígio que estão adquirindo diante da comunidade. Este prestígio não é obtido da noite para o dia. É obtido num constante alimentar o seu entorno, seus parentes, seus brotyré. Note-se que a categoria de parentes que recebe presente no caso da festa da primeira comida é francamente a mesma que esteve envolvida em sua preparação. Sem riqueza não há parentes nem prestígio. Sem parentes não há riqueza nem festas. É preciso manipular as duas fontes de riqueza e prestígio, quais sejam, parentes e festas, para se obter reconhecimento público. Ao me perguntar se eu era uma tori i-tyhy, uma tori "de verdade" ou uma tori rica, Lahiri estava me perguntando tanto se eu tinha uma família numerosa quanto se eu tinha bens materiais em abundância.

Da festa que me foi relatada, o pai, Lahiri, foi quem primeiro me contou e fez questão de mostrar as filmagens. Lahiri não é filho primogênito. Ele é o terceiro filho, segundo homem. Sua liderança na aldeia é proeminente. Entretanto, devido à preferência pela primogenitura, sua sucessão a seu pai na liderança da aldeia não está garantida. Seu irmão mais velho, Kleber, seria o natural sucessor de Carlos Waximakuri. Entretanto, Kleber não vem obtendo reconhecimento público daquela proeminência que o levaria a ser cacique.

Kleber tem uma família "desestruturada" para os padrões Karajá. Sua esposa, que é Tapirapé, não mora em Hãwalorá e sim em Urubu Branco, a maior aldeia Tapirapé. Note-se que o fato de a esposa ser Tapirapé não implica, em Hãwalorá, uma perda da preferência. A esposa de Lahiri também é Tapirapé, bem como a mãe deles. Acredito que um casal que fosse composto de homem e mulher Karajá talvez tivesse alguma preferência numa disputa por legitimidade da liderança, mas isso não é imediatamente dado. Pra- 
ticamente toda a população das três aldeias da barra do Tapirapé (Itxalá, Hãwalorá e Maitâri ${ }^{12}$ ) é composta de gente mestiça entre as duas etnias ${ }^{13}$.

Kleber não vive com a esposa, mas se considera casado com ela. Além disso, desenvolveu habilidades xamânicas e atua como hyri para as três aldeias. Esta atuação não é desprovida de temores. Há quem acredite que ele faça feitiço. Outro de seus irmãos também é hyri mas não ouvi pesarem contra ele acusações de feitiçaria. Acredito que isso se deva à sua situação familiar mais regular: é casado e vive com a esposa e filhos na mesma aldeia, Hãwalorá.

Desta forma, acredito que a execução do ritual público em honra do filho bebê de Lahiri tenha sido um elemento a mais no reconhecimento público de sua proeminência enquanto liderança. Tudo leva a crer que ele substituirá seu pai na condução dos assuntos públicos da aldeia, fenômeno este que estou chamando de política.

O fenômeno brotyré me parece uma versão Karajá daquele fenômeno melanésio que foi chamado por Roy Wagner de pessoa fractal. O brotyré é uma espécie de pessoa jurídica (personne morale na terminologia de Lévi-Strauss) que contém em si muitas pessoas e relações. O sentar-se na esteira junto a outros indivíduos que partilham desse corpo coletivo é reforçar e manter o amálgama dessa pessoa jurídica.

A manutenção deste corpo coletivo só é possível mediante o trabalho de mobilização da parentela e os conhecimentos sobre a confecção de enfeites, o trabalho nas roças e o dispêndio de bens materiais.

\section{Novas aldeias}

Se Peter Rivière tem razão em indicar que o verdadeiro "recurso escasso" na Amazônia é gente, numa abordagem orientada pelo materialismo (RIVIÈRE, 2001), poderíamos sugerir que o chefe Karajá manifesta sua capacidade de influência atraindo gente para junto de si. As aldeias das quais os Karajá mais se recordam e se orgulham são aquelas aldeias grandes onde havia muita festa. A fixação de uma população num mesmo local por um longo tempo é um dos desafios da chefia.

A maioria das aldeias Karajá é de porte pequeno, em torno de 100 a 150 pessoas. Entretanto há aldeias bastante grandes como mencionado acima. Vou me deter na constituição da aldeia Hãwalora e na "política expansionista" de seu cacique, Carlos Waximakuri. Carlos conta ter sido criado como ioló. Sua mãe o enfeitava e o deixava sobre o banquinho. Advertia para não se mover muito: "ela me assustava dizendo que ia cortar meu pinto se eu me mexesse", conta Waximakuri, achando hilária a ameaça da mãe. Seu envolvimento em conflitos internos na aldeia Fontoura o fez se mudar algumas vezes com sua família. Exerceu funções importantes na aldeia São Domingos e foi vereador na cidade de Luciara, MT.

Nos anos anteriores à minha estada em Hãwalora, ele e sua família viviam em Maitâri, uma aldeia na barra do rio Tapirapé onde vivem misturados Karajá e Tapirapé. Na Barra do Tapirapé, município de Santa Terezinha, Mato Grosso, a população é "mestiça" dos dois povos. Mas cada uma de suas aldeias se identifica como pertencendo a um deles e Maitâri é francamente uma aldeia Tapirapé. De formato quase redondo, distante da beira do rio, com uma Casa dos Homens no meio (ANDRADE, 2010). Carlos conta se incomodar com essa distância e com estar entre Tapirapé. Seus netos não sabiam nadar e desconheciam peixes: "Meus netos tinham medo de água, viam um peixe e perguntava o que é isso". Ora, o Karajá é essencialmente um povo ribeirinho e o desconhecimento das referências desta vida pareceram inconcebíveis para Carlos. Vizinha a Maitâri havia as ruínas de uma aldeia Karajá que fora abandonada vários anos antes.

\footnotetext{
${ }^{12}$ Adoto aqui uma grafia diferente da padronizada para a língua Tapirapé. O nome desta aldeia, em sua grafia padronizada, é Mjityri (cf ANDRADE, 2010). Preferi uma grafia facilitada para esclarecer a pronúncia.

${ }^{13}$ Meu uso do termo mestiço aqui é uma franca apropriação da categoria que eles usam, em português.
} 
Era a aldeia Tytemá. Uma disputa que resultou em um assassinato fez com que a população de Tytemá abandonasse o lugar e se espalhasse em diferentes lugares. Alguns fundaram uma outra aldeia chamada "Nova Tytemá".

Carlos decidiu retomar aquele espaço e fundar uma nova aldeia. Abriu o mato junto a um de seus filhos e um cunhado, erguendo casas. Mudou-se com sua mulher e filhos pequenos e posteriormente toda a sua família extensa se mudou para lá também. Assim foi fundada Hãwalorá. A aldeia é composta por sua família extensa e mais a família extensa de Bacuri, irmão de sua esposa.

Enquanto eu estava realizando pesquisa de campo em Hãwalorá, Carlos contava sempre da demanda dos antigos moradores do local, de retornar àquele lugar, de que tanto gostavam. Ele buscou recursos junto à prefeitura para trazer aqueles moradores da Nova Tytemá. Certo dia, por volta das três da tarde chegou a balsa trazendo aqueles antigos moradores da aldeia Tytemá. Aproximadamente trinta pessoas, cachorros, gatos, galinhas, bicicletas, canoas, remos, panelas. Entre os cônjuges dos chegantes havia dois tori, ou seja, não índios.

Nos primeiros dias essa gente se abrigou em casas de parentes distantes. É um momento de recordar laços de parentesco que já haviam se tornado tênues. Nos meses seguintes houve frenética atividade de construção de casas para os novos moradores. Alguns meses depois, quando retornei a Hãwalorá, havia queixas veladas sobre o comportamento de alguns deles. Os tori eram "mau-encarados" e não davam bom dia. O alcoolismo, uma doença infelizmente frequente nas aldeias Karajá, era antes quase inexistente em Hãwalorá graças à moderação exercida por Waximakuri. Depois da chegada do contingente de Nova Tytema, esse lamentável fenômeno também passara a ocorrer em Hãwalorá.

Retornei àquela aldeia no ano seguinte e muito pouco havia restado daquela iniciativa. A maior parte da população que migrou, retornou lentamente a Nova Tytemá. Uma senhora idosa se instalou definitivamente em Hãwalorá junto a um filho de Bacuri. Era querida de todos, muito falante e sempre sorridente. Apesar de não ter parentes próximos ali, sua presença era bem-vinda.

O episódio da tentativa de retorno de parte da população de Nova Tytemá para Hãwalorá é bastante revelador da atuação da chefia. Um dos grandes desafios da chefia karajá é manter uma aldeia grande e alegre. Todas as aldeias são fundadas a partir de um movimento bastante comum: conflito local, emigração de acusados ou então dos descontentes liderados por um cabeça, um wedu, dono, e retomada de algum sítio antigo, já conhecido (antiga roça ou antiga aldeia). Em geral o nome da aldeia é referência a um topônimo conhecido, seja o nome do dono da antiga roça, seja uma referência a uma característica do local. Tytemá é o nome do cascalho que abunda naquele local. Não obtive tradução para Hãwalorá, mas Hãwa significa "aldeia". Entretanto, fixar e assentar aquela população é um processo mais complexo, com muitos meandros e movimentos imprevisíveis.

Manter uma aldeia por longo tempo implica em promover uma boa vida ali dentro. Esta concepção remete a um cotidiano desprovido de conflitos e alegre. A alegria é sempre referida quando se coleta histórias de migrações e fixações. A opção por viver em determinada aldeia está diretamente ligada a essa alegria e à beleza.

Ora, qual é o elemento promotor dessa "alegria"? As festas. E as festas só existem porque existem famílias -ityhy, "ricas" dispostas a patrociná-las em benefício de seus filhos belos. Portanto, a eficácia da chefia enquanto promotora de uma boa vida está diretamente ligada a essa manutenção de uma vida ritual e festiva ativa.

A política expansionista, por assim dizer, é afetada por essas iniciativas. A chegada de um novo contingente populacional traz consigo a possibilidade de conflitos. Afinal, se alteridade é fundamental para a produção do socius, excesso de alteridade é capaz de produzir estranhamento.

Hãwalorá era uma aldeia alegre quando a conheci. E continuou a sê-lo após o retorno dos imigrantes a sua aldeia anterior. No intervalo, problemas de convívio, ou seja, excesso de alteridade, traziam desafios à chefia. Pelo calendário ritual e pelos eventos que ocorreram nesse ínterim ${ }^{14}$, acredito poder inferir que a ausência de festas naquele período foi uma das responsáveis por não se haver fixado mais longamente aquele 
contingente populacional. Manter um equilíbrio entre a promoção dessa vida festiva e alegre ao mesmo tempo em que se mantém um ambiente pacífico é um dos desafios da chefia.

\section{Conclusão}

Neste artigo procurei argumentar que, entre os Karajá, a força que mantém aldeias grandes de forma mais perene é a produção de festas para filhos belos de famílias de prestígio, ou nobres. Acredito que este fenômeno, que é concebido pelos Karajá como a manifestação de riqueza de uma família, é a base da manutenção de unidades políticas maiores.

Para isso, procurei demonstrar que as características da chefia ameríndia, sugeridas por Pierre Clastres estão francamente corretas, mas são insuficientes para explicar a manutenção de grandes aldeias. Restaria explicar, justamente como, diante de um potencial físsil tão grande, diante desta "força centrífuga" da máquina política ameríndia, como é possível o surgimento e a manutenção de aldeias grandes. Nosso argumento neste artigo é que tal é possível com a manutenção de uma vida alegre e pacífica na aldeia. Isto é possível mediante a produção contínua de festas e pelo reconhecimento público da beleza dos filhos de chefes.

Compreender esta concepção de política associada ao belo implica necessariamente em compreender as relações de parentesco dentro das famílias de chefes, que aqui chamei de nobres ${ }^{15}$. Tal como na Melanésia de Godelier, trata-se aqui de um "poder herdado" tanto quanto de um "poder merecido".

\section{Referências}

ANDRADE, Julia M. A. A construção da Takãra em Majtyri: etnografia de uma aldeia Tapirapé. 2010. Dissertação (Mestrado). Universidade Federal Fluminense: Niterói, 2010.

BARCELOS NETO, Aristóteles. A arte dos sonhos - uma iconografia ameríndia. Lisboa: Museu Nacional de Etnologia/Assírio \& Alvim, 2002.

“Festas para um 'nobre': Ritual e (re)produção sociopolítica no Alto Xingu”. Estudios Latinoamericanos. vol. 23, p. 63-90, 2003.

Apapaatai: Rituais de máscaras no Alto Xingu. São Paulo: EdUSP/FAPESP, 2008.

GODELIER, Maurice. La Production des Grands Hommes. Pouvoir et domination masculine chez les Baruya de Nouvelle-Guinée. Paris: Flammarion/Champs Essais, 1996.

GUERREIRO JR., Antonio. Ancestrais e suas sombras. Uma etnografia da chefia Kalapalo e seu ritual mortuário. Campinas: Ed. Unicamp, 2015.

\footnotetext{
${ }^{14}$ Hãwalorá sofreu entre 2010 e 2012, junto com outras aldeias Karajá, uma sequência de episódios de suicídio de jovens., sobretudo homens recém-casados mas não apenas eles. Uma morte provoca a interrupção imediata de qualquer festividade. A morte de pessoas jovens conduz a um luto ainda mais prolongado uma vez que eles são em geral quem mais anima a vida ritual, se envolvendo na confecção das máscaras e na performance dos rituais. Ver Nunes (2019) e Schiel (2019) para uma abordagem sobre esse fenômeno.

${ }^{15}$ Sigo, portanto, a nomenclatura que tem sido usada por Aristóteles Barcelos Neto (2008) e Antônio Guerreiro Jr. (2015) na região do Alto Xingu.
}

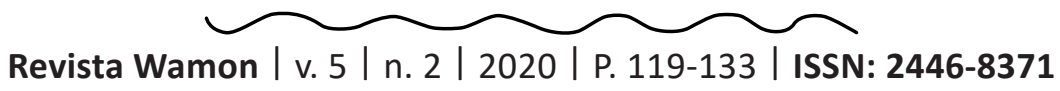


LOPES DA SILVA, Aracy. Nomes e amigos: da prática xavante a uma reflexão sobre os Jê. São Paulo: FFLCH-USP, 1986.

NUNES, Eduardo. "Do feitiço de enforcamento e outras questões" In: CAMPO ARÁUZ, Lorena \& APARÍCIO, Miguel. (Org.) Etnografías del suicídio en la América del Sur. Quito, Abya-Yala, 2017, p. 259-284.

MAUSS, Marcel. O Ensaio sobre a Dádiva. São Paulo: Cosac Naify, 2013.

RIVIÉRE, Peter. Indivíduo e Sociedade na Guiana. São Paulo: EDUSP, 2001.

RODRIGUES, Patrícia. O Povo do Meio: tempo, cosmo e gênero entre os Javaé da Ilha do Bananal. 1993. Dissertação (Mestrado). Universidade de Brasília: Brasília, 1993.

SCHIEL, Helena. "Os itxoí ou grupos de praça Karajá. As organizações triádicas existem?" Campos. Revista de Antropologia. vol. 13 (2), p. 24-38, 2012.

"Os Sofrimentos do jovem Tebutxué". In: ARÁUZ, Lorena \& APARÍCIO, Miguel. (Org.) Etnografías del suicídio en la América del Sur. Quito, Abya-Yala, 2017, pp. 245-258.

TORAL, André A. Cosmologia e Sociedade Karajá. 1992. Dissertação (Mestrado). Museu Nacional/UFRJ: Rio de Janeiro, 1992.

TURNER, Victor. O Processo Ritual. Estrutura e anti-estrutura. Petrópolis: Ed. Vozes, 1974.

VAN GENNEP, Arnold. Os Ritos de Passagem. Petrópolis: Ed Vozes, 2011.

VIVEIROS DE CASTRO, Eduardo. "Atualização e contraefetuação do virtual: o processo do parentesco". In: VIVEIROS DE CASTRO, Eduardo. A Inconstância da Alma Selvagem. São Paulo: Cosac Naify, 2002.

WAGNER, Roy. “The Fractal Person”. In: STRATHERN, Marilyn e GODELIER, Maurice (Org.). Big Men and Great Men: Personifications of Power in Melanesia. Cambridge: Cambridge University Press, 1991.

Recebido em 30/10/2020

Aceito em 23/11/2020 
